\title{
Explanation of Tautomerism and Isomerization in Terms of the Magnetic Field
}

\author{
Aibassov Yerkin", Yemelyanova Valentina, Tussupbayev Nessipbay, Shakieva Tatyana, Yerzhanova Zhadyra, \\ Bulenbayev Maxat and Blagikh Evgeniy \\ Research Institute of New Chemical Technologies and Materials, Kazakh National University Al-Farabi, Almaty 005012, Kazakhstan
}

\begin{abstract}
A study of the influence of magnetic field on the tautomerism, the authors proposed a new method for predicting possible new intra- and intermolecular rearrangements due to tautomerism. The authors have proposed a general mechanism of possible rearrangements and tautomerism.
\end{abstract}

Key words: Tautomerism, isomerism, benzidine rearrangement, magnetic field.

\section{Introduction}

In recent years, many new rearrangements, are caused by tautomerism. Therefore, it was important to study the influence of magnetic field on tautomerism.

Scientific novelty is that this work is a first attempt to explain the tautomerism in terms of the magnetic field.

The aim is to study tautomerism in terms of magnetic field.

\section{Theory}

It is known that the phenomenon of tautomerism is that the material of certain composition and molecular weight exists as an equilibrium mixture of two or more isomers, easily transformed into each other [1-3].

The term "tautomerism" refers essentially dual reactivity, i.e. phenomenon in which a substance enters into chemical reactions in accordance with the two (or more) for a possible structural formulas. Reason tautomerism hydrocyanic acid is not the existence of discrete molecules $\mathrm{H}-\mathrm{C} \equiv \mathrm{N}$ and $\mathrm{H}-\mathrm{N}=\mathrm{C}$, are capable of mutual conversion, and in that the hydrogen is continuously oscillates (similar oscillations double bonds occurring in the molecule, benzene) between the

\footnotetext{
*Corresponding author: Aibassov Erkin Zhakenovich, professor, research fields: metalorganic chemistry of uranium and thorium, $\mathrm{As}, \mathrm{Sb}$ and $\mathrm{Bi}$.
}

nitrogen atoms and carbon so that all hydrocyanic acid molecules have the same structure.

If movement due to tautomerism in the molecule atoms or groups as cations, such processes are called kationotropnymi tautomeric transformations. Many cases studied tautomerism due to migration of hydrogen cations (protons) from one molecule to another atom. Such tautomeric transformations called Prototropic; they determine, for example, the following types of tautomerism:

$$
\begin{gathered}
-\mathrm{C}(=\mathrm{O})-\mathrm{C}(\mathrm{H}) \mathrm{H}-\leftrightarrow-\mathrm{C}(\mathrm{OH})=\mathrm{CH}-(\text { keto-enol } \\
\quad \text { tautomerism) } \\
-\mathrm{C}(=\mathrm{O})-\mathrm{NH}-\leftrightarrow-\mathrm{C}(\mathrm{OH})=\mathrm{N}-(\text { lactam-lactim } \\
\quad \text { tautomerism) } \\
-\mathrm{C}(=\mathrm{NH})-\mathrm{NH}-\leftrightarrow \begin{array}{c}
\mathrm{C}\left(\mathrm{NH}_{2}\right)=\mathrm{C}=(\text { ketimine-enamine } \\
\text { tautomerism) }
\end{array} \\
\mathrm{O}=\mathrm{N}-\mathrm{CH}-\leftrightarrow \mathrm{HO}-\mathrm{N}=\mathrm{C}= \\
\text { (nitroso-izonitrozotautomeriya) }
\end{gathered}
$$

If the authors summarize all known tautomerism, they get the reaction of three molecules of the general equation:

$$
\mathrm{X}+\mathrm{Y}+\mathrm{Z} \leftrightarrow \mathrm{XYZ}+\mathrm{YZX}+\mathrm{ZXX}+\mathrm{YXZ}+\mathrm{ZYX},
$$
which has $2 \mathrm{~N}-1$ option, i.e. 5 possible products.

If $\mathrm{T}=6$, then the authors will get 11 different products.

Prototropic transformation accelerated as acids and bases. 
Much less studied anionotropnye tautomeric transformations, when the atoms or groups of atoms migrate in the form of anions.

An example may serve anionotropnogo transformation observed in the specific conditions tautomerism substituted unsaturated hydrocarbons with Deputy X (halogen, acyloxy) in the so-called "allyl" position:

\section{$\mathrm{R}-\mathrm{C}(\mathrm{X}) \mathrm{H}-\mathrm{CH}=\mathrm{CH}_{2} \leftrightarrow \mathrm{R}-\mathrm{CH}=\mathrm{CH}-\mathrm{C}(\mathrm{X}) \mathrm{H}_{2}$}

Tautomeric equilibrium is characterized by its position and velocity setting. The position of the tautomeric equilibrium, and the rate of establishment are quite different. They depend on the structure of the tautomeric material nature of the solvent and temperature.

It should be noted that between the phenomena of tautomerism isomer and no sharp boundary. Substances isomeric under certain conditions, other conditions may undergo tautomeric transformations. For example, the isomeric crotonic acid and vinylacetic resistant under normal conditions, can be converted into each other in a hot alkaline solution:

\section{$\mathrm{CH}_{2}=\mathrm{CH}-\mathrm{CH}_{2}-\mathrm{COO}^{-} \leftrightarrow \mathrm{CH}_{3}-\mathrm{CH}=\mathrm{CH}-\mathrm{COO}^{-}$}

Propyl bromide and isopropyl bromide, which are normally stable isomers at $250^{\circ} \mathrm{C}$ (sealed tube) form an equilibrium of mixture:

$$
\mathrm{CH}_{3}-\mathrm{CH}_{2}-\mathrm{CH}_{2}-\mathrm{Br} \leftrightarrow \mathrm{CH}_{3}-\mathrm{CHBr}-\mathrm{CH}_{3}
$$

Another type of tautomeric transformation that occurs without migration of an atom or group of atoms - valence tautomerism - reversible interconversion of valence isomers. The latter are isomers that can be converted into each other as a result of redistribution bonds. Valence tautomerism includes some sigmatropic rearrangement, electrocyclic reaction and ring-ringed rearrangements.

\section{Results and Discussions}

Electric and magnetic fields of their energy are proportional to the square of the field strength. The energy density of the electromagnetic field is the sum of the energy densities of electric and magnetic fields.

$$
\mathrm{u}=\mathrm{E} \cdot \mathrm{D} / 2+\mathrm{B} \cdot \mathrm{H} / 2 .
$$

In a vacuum:

$$
\mathrm{u}=\frac{\varepsilon_{0} E^{2}}{2}+\frac{B^{2}}{2 \mu_{0}}=\varepsilon_{0} \frac{E^{2}+c^{2} B^{2}}{2}=\frac{E^{2} / c^{2}+B^{2}}{2 \mu_{0}}
$$

where, $E$-electric field strength, $B$-magnetic induction, $D$-electric induction, $H$-magnetic field strength, $c$-speed of light, $\varepsilon_{0}$ - dielectric constant and $\mu_{0}$-magnetic constant.

Then,

$$
u=\frac{E \times D+B \times H}{8 \pi}
$$

The energy of the electromagnetic fields in the resonant circuit:

$$
\mathrm{W}=\frac{C U^{2}}{2}+\frac{L I^{2}}{2}
$$

where, $U$-voltage circuit, $C$-electrical capacitance of the capacitor, $I$-amperage, $L$-inductance of the coil or coil with a current.

The electromagnetic wave energy flux density is determined by the Poynting vector $C$.

The Poynting vector is $S=E \times H$ vector product strengths of electric and magnetic fields) and is directed perpendicular vector $\mathrm{E}$ and $\mathrm{H}$. This is naturally in line with the property of transverse electromagnetic waves.

Hence the authors see that the tautomerism electron moves in a spiral and can migrate from one to another atom in the molecule, causing spatial tautomerism.

Another way of electron motion and accumulation of electron density between the two atoms is doubling or tripling of the chemical bond, which leads to the valence tautomerism.

Thus, the authors were asked to consider the tautomerism as a result of the magnetic field of each atom to neighboring atoms within a single molecule.

\section{Conclusions}


Thus, as a result of studying the influence of the magnetic fields on tautomerism, the authors obtained the following results.

The authors have proposed a new method for predicting possible new intra- and intermolecular rearrangements due to tautomerism.

The authors propose a new generalized formula for determining possible new rearrangements in organic and organometallic chemistry.

The authors propose a general mechanism of possible rearrangements and tautomerism.

The authors suggest that mild conditions by the action of molecular iodine benzene, may form a six-membered rings with one $\mathrm{C}_{6} \mathrm{H}_{4}$ and $\mathrm{C}_{6} \mathrm{H}_{2}$ two triple bonds.
The practical significance of the work lies in the fact that on the basis of the results it can predict the possibility of opening new rearrangements, and tautomeric transformations in organic and organometallic chemistry.

\section{References}

[1] Antonov, L. 2013. Tautomerism: Methods and Theories. 1st ed. Weinheim.

[2] Katritzky, A. R., and Elguero, J. 1976. The Tautomerism of Heterocycles. New York: Academic Press.

[3] Roman, M. B. 2009. "Tautomeric Equilibrium and Hydrogen Shifts in Tetrazole and Triazoles: Focal-Point analysis and ab Initio Limit." J. Chem. Phys. 131 (15): 154307. 